\title{
Solar Recovery of Metal Alloys
}

\author{
Odilhuja Parpiev ${ }^{1}$, Mukhammad-Sultan Payzullakhanov ${ }^{1}$, Bum Sung Kim², Erkin Nodirmatov ${ }^{1}$ \\ ${ }^{I}$ Material sciences institute Uzbekistan academy of sciences, Tashkent city, 100084, Chingiz Aytmatov street 2 \\ ${ }^{2}$ KIRAM Korea Republik, Inchxon
}

*Corresponding Author: Odilhuja Parpiev, Material sciences institute Uzbekistan academy of sciences, Tashkent city, 100084, Chingiz Aytmatov street 2

\begin{abstract}
The technogenic wastes of Metallurgical Plant, containing non-ferrous metals - gold, silver, as well as iron and copper, were investigated. The concentrated solar radiation flux at the Big Solar Furnace with a thermal power of $1 \mathrm{MW}$ was used to heat industrial waste with the addition of coke (5 wt.\%) And calcium oxide (10 wt.\%) In a graphite crucible. Under the influence of concentrated solar radiation with a flux density of 70-100 W/ cm2, the material melted and the melt drained into water. In the liquid state in the presence of carbon, the process of metal reduction from oxide states proceeded. The crystallization process upon cooling of the melt in water had the character of segregation, i.e. Separate crystallization of metals and ceramics. As a result of this, individual granules of metal and ceramics of various sizes and shapes accumulated in water. Quantitative analysis showed that the processing of industrial waste in a stream of concentrated solar radiation of high density allows you to extract metals (25 wt. \%) From them that can be used in metallurgy. And the remaining ceramic part (75 wt.\%) Is calcium silicate, which can be used to create lining plates.
\end{abstract}

\section{INTRODUCTION}

The current population growth rate, especially in cities with developed industry, undoubtedly causes an increase in the consumption of energy and mineral resources. Consequently, the question arises of the need to develop new methods of mining, processing accumulated from year to year man-made waste $(\mathrm{TH})$.

It is known that the metallurgical industry is one of the largest sources of $\mathrm{CO} 2$ emissions [1]. As noted in [2] in 2000, ferrous metallurgy accounts for about $4.1 \%$ of global CO2 emissions. According to [3], in the production of pig iron, $19.6 \%$ of $\mathrm{CO} 2$ emissions are from sintering and $62 \%$ from blast furnaces. The specific energy consumption in an electric arc furnace is $310-640 \mathrm{kWh} / \mathrm{t}$ of steel [4]. In this case, coke is used as a reducing agent. The amount of CO2 emissions in this case is 1630-1960 $\mathrm{kg} / \mathrm{t}$ of steel.

On the other hand, the metallurgical industry is not waste-free. As analysis shows, at present, the total amount of TO is estimated at billions of tons containing precious metals: gold, silver, copper. The associated extraction of metals and other components present in the maintenance would increase the complexity of the use of raw materials and make processing economically viable [5].

The main directions of waste management are focused on their incineration or their removal to landfills and tailings, requiring the removal of large land plots. Large amounts of money are spent annually on the maintenance of dump farms. A large amount of slag determines the relevance of the problem of their rational use. The storage of such waste requires huge areas and adversely affects the environment. Their use in the construction industry leads not only to the irretrievable loss of valuable components, but is also difficult due to the presence of heavy metal oxides in them [6].

Consequently, the current development of maintenance processing is not profitable and not environmentally friendly. Therefore, these have not yet gone beyond the scope of search laboratory research. 
However, $\mathrm{CO} 2$ emissions in metallurgy can be reduced by using a concentrated solar energy stream instead of burning coke. Concentrated solar energy has great potential for use at high temperatures [7]. These applications include: material processing (welding and cladding, surface treatment, coatings and surface hardening and powder metallurgy), synthesis and processing of non-metallic materials (ceramics, fullerenes, carbon nanotubes, calcium aluminate cements [8] and lime production) and metallurgical processes ( production of silicon and aluminum, $\mathrm{ZnO} / \mathrm{Zn}$ pairs). Concentrated solar heat is still not widely used in steelmaking. In [9], the process of iron oxidation under the influence of solar energy on steel was studied and $\mathrm{Fe} 3 \mathrm{O} 4$ without impurities was obtained for use in the production of high-quality steel and aluminothermic welding of railway rails. Another study was conducted to study the effect of concentrated solar energy in iron oxides - the decomposition of magnetite at temperatures above the melting point of this phase in air and argon [10]. In [11], the reduction of iron (III) oxide by graphite in a solar furnace at high temperatures (1300-2390 K) with a yield of Fe: $78 \%$ was studied. In [12], the joint production of iron and synthesis gas was studied by reducing magnetite in $\mathrm{CH} 4$. The carbothermic reduction of iron (III) oxide and manganese (IV) oxide was studied in [13].

Thus, solar furnaces can be sources of heat during the processing of TO without polluting both the product itself and the environment with carbon dioxide.

The only Big Solar Furnace in Central Asia was commissioned in 1987 (Fig. 1.). There are two such solar ovens in the world, the first of which is located in France (Odeo).

The Big Solar Furnace is a complex optical-mechanical system with automatic control and consists of such components as the heliostat zone, concentrator and technological tower. The reflecting surface of 62 heliostats is $3022.5 \mathrm{~m} 2$, the paraboloid type concentrator consists of 10700 facets with a total reflecting surface of $2166.75 \mathrm{~m} 2$.

The Large Solar Furnace is able to concentrate the solar flux in the focal plane to a density of $600 \mathrm{~W} /$ $\mathrm{cm} 2$. One of the distinguishing parameters of the Big Solar Furnace as a technological tool is its high heating rate of the material $(1500 \mathrm{deg} / \mathrm{min})$ to a temperature of $2000-270{ }^{\circ} \mathrm{C}$, in contrast to traditional heating devices (electric, laser, plasma, electric arc). Melting of materials under the influence of concentrated solar radiation of high density is based on the processes of light absorption of materials. In order to obtain materials with desired properties, the melts can be cooled at various speeds - quenching on a metal sheet, quenching in water, quenching in a stream of water or inert gases [14].

\section{EXPERIMENTAL RESULTS AND THEIR DISCUSSION}

The results of a chemical analysis of the composition of the waste from the metallurgical plant are shown in Table 1. As can be seen from Table 1, the waste is mainly represented by iron silicates; pyroxene-type minerals are also contained. The waste also contains metals: gold, silver and copper.

Table1. Composition of the waste from the metallurgical plant

\begin{tabular}{|l|l|l|l|l|l|l|l|}
\hline Element & $\mathrm{Au}$ & $\mathrm{Ag}$ & $\mathrm{CuO}$ & $\mathrm{SiO}_{2:}$ & $\mathrm{CaO}$ & $\mathrm{Al}_{2} \mathrm{O}_{3}+\mathrm{MgO}$ & $\mathrm{Fe}-\mathrm{FeO}-\mathrm{Fe}_{2} \mathrm{O}_{3}$ \\
\hline Content, $\%$ & $0.52 \Gamma / \mathrm{T}$ & $1.72 \Gamma / \mathrm{T}$ & 0.52 вес.\% & 34вес.\% & $5-7$ вес.\% & 5-6 вес.\% & 45 вес. $\%$ \\
\hline
\end{tabular}

A mixture of the following composition was made for melting the waste from the metallurgical plant at BSP: $5 \mathrm{~kg} \mathrm{TO}+0.5 \mathrm{~kg} \mathrm{CaO}+0.35 \mathrm{~kg}$ coke. The mixture was stirred in a ball mill for 2 hours, dried in an oven at $4500 \mathrm{C}$ for 10 hours. The mixture was placed in a graphite crucible in the shape of a cylinder Ø200 $200 \mathrm{~mm}$ high with a hole Ø12 in the lower part.

The crucible was installed in the focal plane of the BSP. Concentrated solar radiation with a density of 70 and $100 \mathrm{~W} / \mathrm{cm} 2$ is directed at the target - crucible. The process of melting the material was monitored through a television vision system.

After holding the crucible with the material under the influence of a stream of concentrated solar radiation, liquid flowed off from the bottom of the crucible - dropping drops of liquid into water.

Under the influence of concentrated solar radiation with a flux density of $100 \mathrm{~W} / \mathrm{cm} 2$, the material melted and the melt drained into water. In the liquid state in the presence of carbon, the process of metal reduction from oxide states proceeded. The crystallization process upon cooling of the melt had the character of segregation, i.e. Separate crystallization of metals and ceramics. As a result of this, individual granules of metal and ceramics of various sizes and shapes accumulated in water. 
Quantitative analysis showed that the processing of industrial waste in a stream of concentrated solar radiation of high density allows you to extract metals (25 wt.\%) From them that can be used in metallurgy. And the remaining ceramic part (75m.\%) Is calcium silicate, which can be used to use the creation of lining plates.

\section{CHARACTERIZATION OF METAL AND CERAMIC WASTE}

Analysis of metal waste was carried out to determine the elemental composition and microstructure. This analysis will help determine the value of the waste and recyclable elements present. In addition, disposal methods are also discussed.

\section{CHARACTERISTICS OF METAL WASTE}

Figure 2 shows images of scanning electron microscopy.

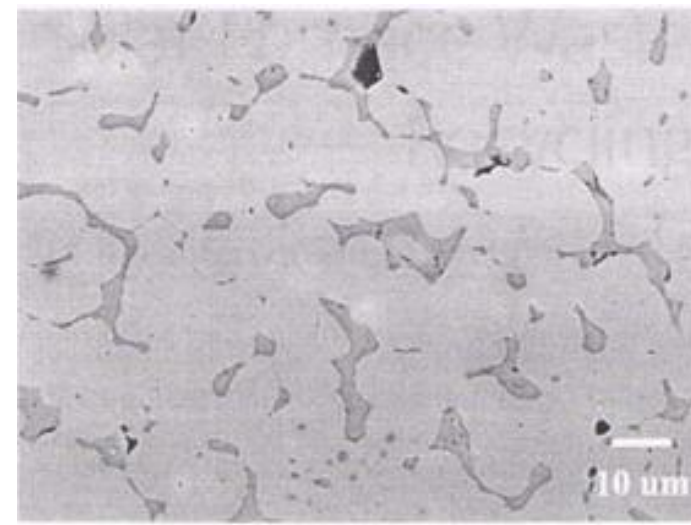

Type 1 microstructure

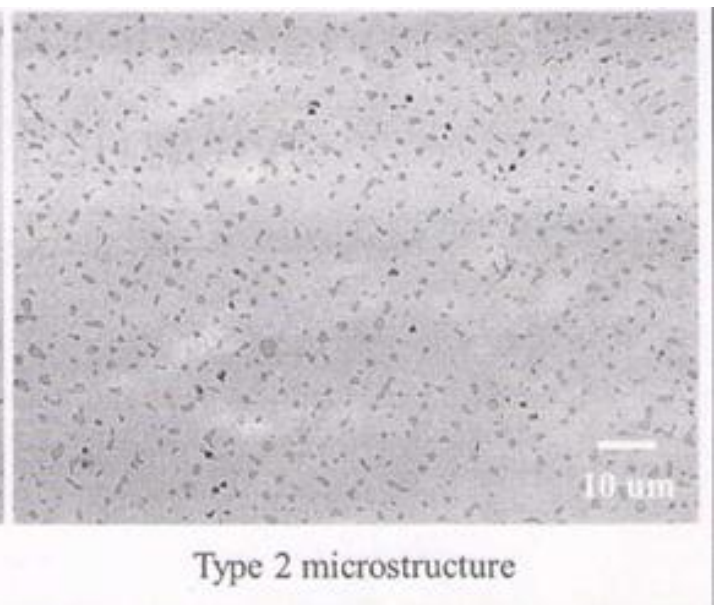

Type 2 microstructure

Fig2. SEM image of the microstructure of materials

Figure 2 shows an SEM analysis of metal waste. The analysis revealed a binary phased microstructure. Two types of microstructures were observed in the waste particles. Two types of microstructures are referred to as type 1 and type 2 microstructures. Most of the waste particles consisted of type 1 microstructures. In this microstructure, the secondary dark phase had a random morphology and a rough size. However, in the type 2 microstructure, the secondary phase was much finer. The phase fraction of the secondary phase was about $11-13 \%$ in both types of microstructures. An analysis of the phase composition was carried out using elemental analysis.
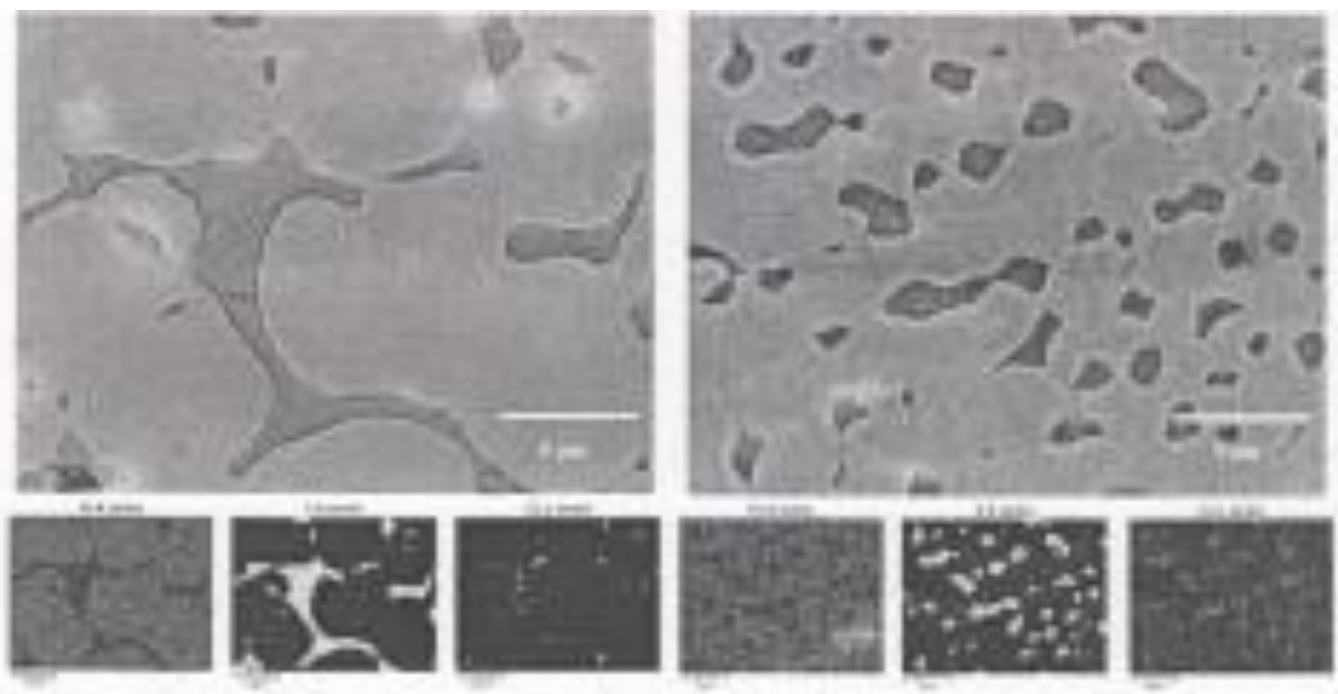

Fig3. Elemental analysis of two types of microstructures [(red) $\mathrm{Fe}$, (yellow) $\mathrm{S}$, (magenta) $\mathrm{Cu}]$

Figure 4 shows the elemental mapping of the microstructure of two types. Three key components were present in two phases, namely $\mathrm{Fe}, \mathrm{Cu}$, and $\mathrm{S}$. The bright phase in both microstructures was mainly $\mathrm{Fe}$ with a small amount of $\mathrm{Cu}$, while the dark intermetallic phase consisted of $\mathrm{Fe}, \mathrm{Cu}$, and $\mathrm{S}$. The exact composition of both phases, which contains other minor elements, are given in table 2. 


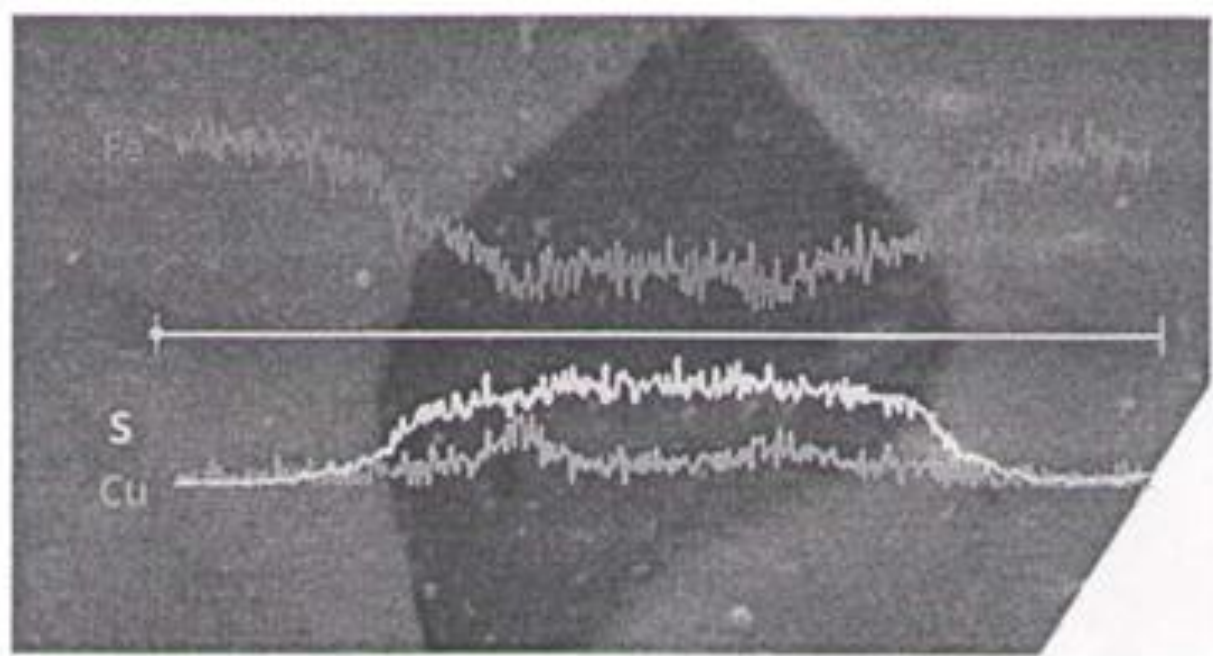

Fig4. Linear analysis of the distribution of two-phase elements [(red) $\mathrm{Fe}$, (yellow) $\mathrm{S}$, (magenta) Cu]

Table2. The elemental composition of the two-phase phase inside the microstructure

\begin{tabular}{|c|c|c|c|}
\hline \multicolumn{2}{|c|}{ Bright phase } & \multicolumn{2}{c|}{ Dark phase } \\
\hline Element & Content, $\%$ & Element & Content, $\%$ \\
\hline $\mathrm{C}$ & 5.01 & $\mathrm{C}$ & 5.41 \\
\hline $\mathrm{S}$ & 0.76 & $\mathrm{~S}$ & 21.57 \\
\hline $\mathrm{P}$ & 0.31 & $\mathrm{P}$ & 0.42 \\
\hline $\mathrm{Fe}$ & 91.41 & $\mathrm{Fe}$ & 64.84 \\
\hline $\mathrm{Cu}$ & 2.51 & $\mathrm{Cu}$ & 7.74 \\
\hline Total & 100.00 & Total & 100.00 \\
\hline
\end{tabular}

According to quantitative analysis, copper is present in a greater amount in the intermetallic phase compared to the matrix. However, they may differ from the exact values.

The linear map of the two phases shown in Fig. 4 clearly distinguishes the change in composition between the two phases. In the matrix phase, the main element is $\mathrm{Fe}$ with a small amount of $\mathrm{Cu}$ and very low $\mathrm{S}$, while in the second phase, the Fe content decreases significantly with a sharp increase in the content of $\mathrm{S}$ and $\mathrm{Cu}$. The XRD profile of metal waste is shown in Fig. 5.

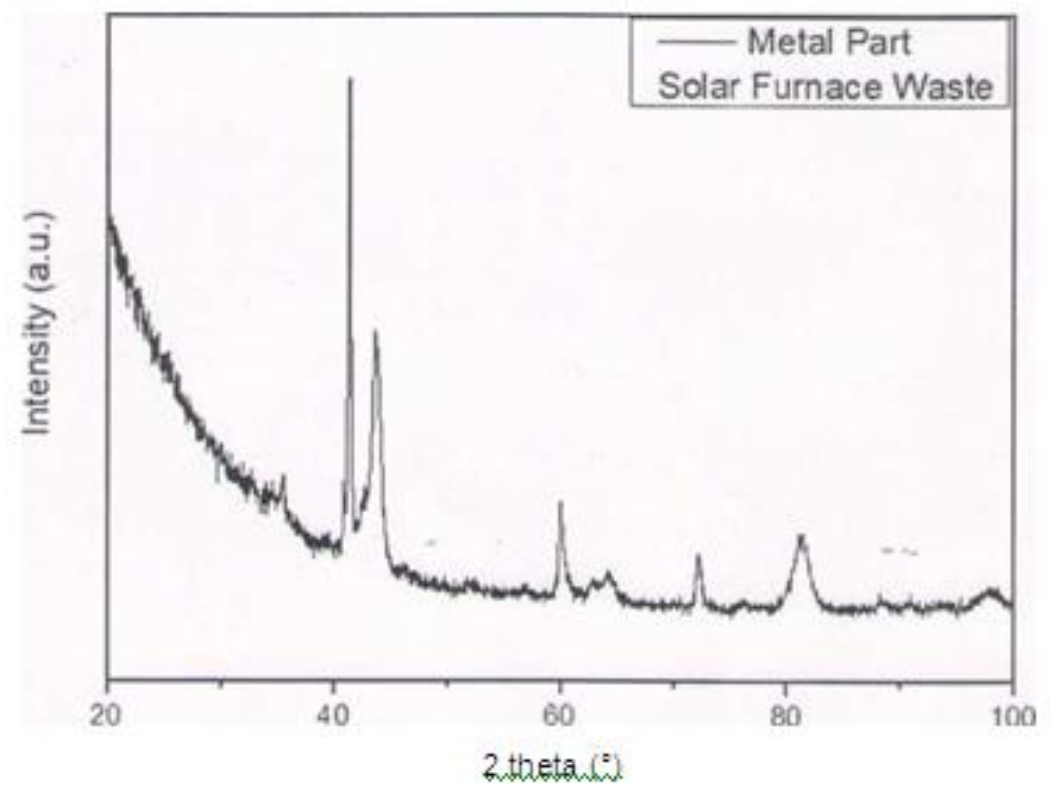

Fig5. $X$-ray analysis of the waste sample

After comparing the resulting template with available XRD cards, it was found that it does not very well agree with any phases present in the $\mathrm{Fe}-\mathrm{Cu}-\mathrm{S}$ system. This may be due to the metastable nature of the sample. Sample homogenization can lead to a sharper XRD profile. 


\section{CHARACTERISTICS OF CERAMIC WASTE}

Figure 6 shows the polished surface of ceramic waste. The back-scattered image of the sample showed that the sample is single-phase, since the secondary phase was not visible. To confirm this, a linear surface mapping was performed.

Linear mapping confirms the previous hypothesis that the sample is single-phase. The distribution of elements along the sample was significantly uniform. However, the composition of the ceramics was rather complicated. Elemental analysis is shown in table 3.

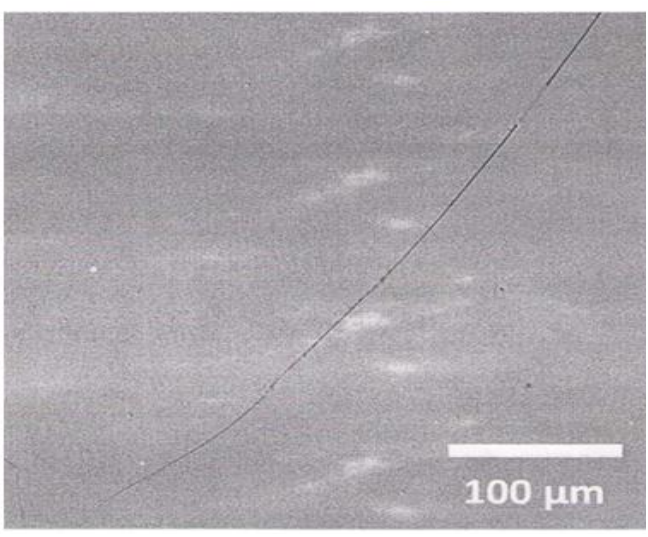

Fig6. SEM image of the waste microstructure

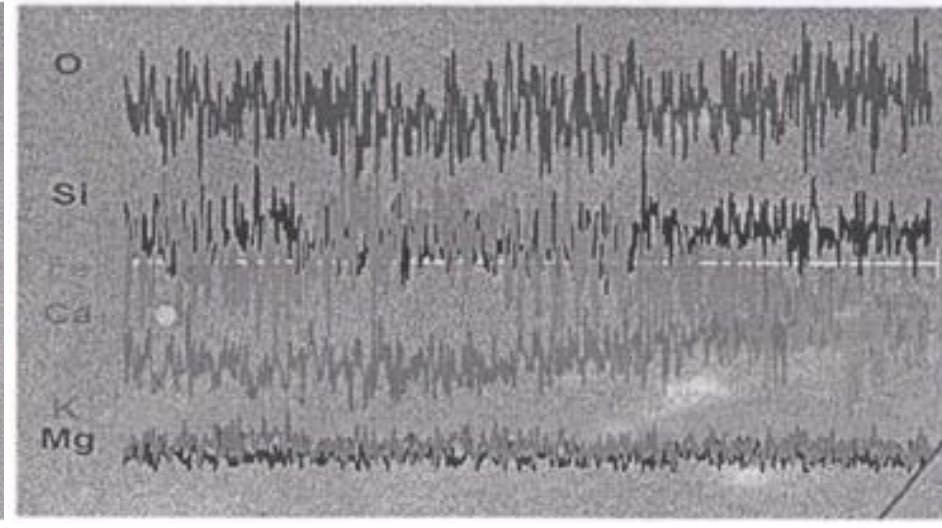

Fig7. SEM image of the waste microstructure

The elemental composition shows that the ceramic part, representing the silicate calcium $\mathrm{SiCaMgO}$, contains a large amount of $\mathrm{Si}$ and $\mathrm{Fe}$, as well as $\mathrm{Ca}$, while a certain amount of $\mathrm{A} 1$ and $\mathrm{Mg}$ is present (Fig. 7).

Table3. The elemental composition of the two phases present inside the ceramic

\begin{tabular}{|l|l|l|l|l|l|l|l|l|l|l|l|}
\hline Element & $\mathrm{C}$ & $\mathrm{O}$ & $\mathrm{Mg}$ & $\mathrm{Al}$ & $\mathrm{Si}$ & $\mathrm{S}$ & $\mathrm{K}$ & $\mathrm{Ca}$ & $\mathrm{Ti}$ & $\mathrm{Fe}$ & Total: \\
\hline Content, \% & 10.08 & 42.27 & 2.43 & 2.84 & 12.58 & 0.33 & 1.09 & 10.54 & 0.20 & 17.64 & 100.00 \\
\hline
\end{tabular}

In fig. 8 shows the X-ray diffraction pattern of the ceramic part of the fused material on the Big Solar Furnace. The analysis showed that this pattern corresponds to the $\mathrm{Si} 2 \mathrm{CaMgO} 6$ compound

Thus, the charge is melted in a graphite crucible in the focal plane of the BLB at a flux density of 100 $\mathrm{W} / \mathrm{cm} 2$. Drainage of the melt into water contributed to the separate crystallization of metal alloys 25 wt.\% $(\mathrm{FeCu})$ and 75 wt.\% Ceramics $(\mathrm{SiCaMgO})$.

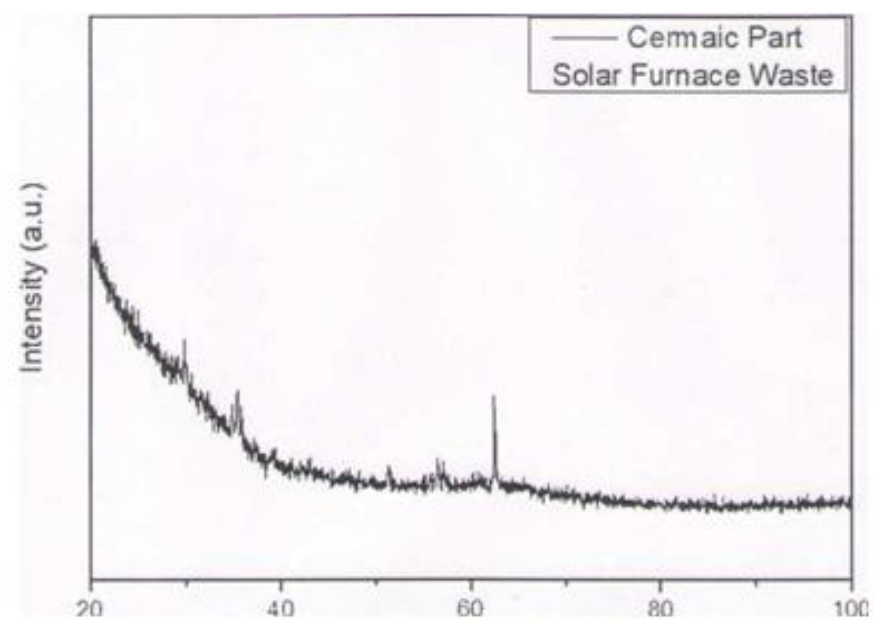

Fig8. $X$-ray analysis of ceramic waste

\section{CONCLUSiOnS}

Consequently, the concentrated solar radiation flux at the Big Solar Furnace with a thermal power of 1 MW can be used for the processing of industrial wastes (MOT) of the Almalyk mining and metallurgical plant. By melting the mixture "TO +5 wt.\% Coke +10 wt.\% Calcium oxide" in a 
graphite crucible under the influence of concentrated solar radiation with a flux density of 70-100 W / $\mathrm{cm} 2$, followed by the discharge of the melt into water, separately reduced metal alloys and ceramics can be obtained. Quantitative analysis showed that the processing of industrial waste in a stream of concentrated solar radiation of high density allows you to extract metals (25 wt.\%) From them that can be used in metallurgy. And the remaining ceramic part (75 wt.\%) Is calcium silicate, which can be used to create lining plates.

As the analysis shows, the specific consumption of coke in metallurgy is about $-0.5-0.6 \mathrm{t} / \mathrm{t}$. On the other hand, the thermal power of the BSP (1 MW) corresponds to the burning of $113 \mathrm{~kg}$ of coal. And when burning such an amount of coal, $192 \mathrm{~m} 3$ of $\mathrm{CO} 2$ is formed, polluting the environment.

Concentrated solar energy can be an alternative in metallurgical processes. Despite the fact that interesting results were obtained on the reduction of iron from its oxide, further studies are neede to consider solar metallurgy as an alternative to well-studied traditional processes.

\section{REFERENCES}

[1] Pardo, N.; Moya, J.A. Prospective scenarios on energy efficiency and $\mathrm{CO}_{2}$ emissions in the European iron \& steel industry. Energy 2013, 54, 113-128.

[2] Wang, K.; Wang, C.; Lu, X.; Chen, J. Scenario analysis on $\mathrm{CO}_{2}$ emissions reduction potential in China's iron and steel industry. Energy Policy 2007, 35, 2320-2335.

[3] Ariyama, T.; Sato, M. Optimization of ironmaking process for reducing $\mathrm{CO}_{2}$ emissions in the integrated steel works. ISIJ Int. 2006, 46, 1736-1744. [CrossRef]

[4] Kirschena, M.; Badr, K.; Pfeifer, H. Influence of direct reduced iron on the energy balance of the electric arc furnace in steel industry. Energy 2011, 36, 6146-6155.

[5] K.O. Potapov, V.E. Roshchin. Selective recovery and pyrometallurgical extraction of iron from sludge from smelting production // Bulletin of the South Ural State University. Series: Metallurgy. 2014, t. 14, No. 3

[6] Harchenko E.M. Ulieva G.A. Egorova T.G. Rakhimbekov S.S. Slag processing of smelting production // International Journal of Applied and Fundamental Research. 2015. No. 7. P. 30-33.

[7] Fernández-González, D.; Ruiz-Bustinza, I.; González-Gasca, C.; Piñuela-Noval, J.; Mochón-Castaños, J.;Sancho-Gorostiaga, J.; Verdeja, L.F. Concentrated solar energy applications in materials science and metallurgy. Sol. Energy 2018, 170, 520-540. [CrossRef] Metals 2018, 8, 87324 of 25

[8] Fernández-González, D.; Prazuch, J.; Ruiz-Bustinza, I.; González-Gasca, C.; Piñuela-Noval, J.; Verdeja, L.F.Solar synthesis of calcium aluminates. Sol. Energy 2018, 171, 658-666.

[9] Ruiz-Bustinza, I.; Cañadas, I.; Rodríguez, J.; Mochón, J.; Verdeja, L.F.; García-Carcedo, F.; Vázquez, A.Magnetite Production from Steel Wastes with Concentrated Solar Energy. Steel Res. Int. 2013, 84, $207-$ 217.

[10] Sibieude, F.; Ducarroir, M.; Tofighi, A.; Ambriz, J. High temperature experiments with a solar furnace: The decomposition of $\mathrm{Fe}_{3} \mathrm{O}_{4}, \mathrm{Mn}_{3} \mathrm{O}_{4}$, CdO. Int. J. Hydrogen Energy 1982, 7, 79-88.

[11] Steinfeld, A.; Fletcher, E.A. Theoretical and experimental investigation of the carbothermic reduction of $\mathrm{Fe}_{2} \mathrm{O}_{3}$ using solar energy. Energy 1991, 16, 1011-1019.

[12] Steinfeld, A.; Kuhn, P.; Karni, J. High-temperature solar thermochemistry: Production of iron and synthesis gas by $\mathrm{Fe}_{3} \mathrm{O}_{4}$-reduction with methane. Energy 1993, 18, 239-249.

[13] Mochón, J.; Ruiz-Bustinza, I.; Vázquez, A.; Fernández, D.; Ayala, J.M.; Barbés, M.F.; Verdeja, L.F. Transformations in the Iron-Manganese-Oxygen-Carbon System Resulted from Treatment of Solar Energy with High Concentration. Steel Res. Int. 2014, 85, 1469-1476.

[14] R.Y. Akbarov, M.S. Paizullakhanov. Characteristic features of the energy modes of a large solar furnace with a capacity of $1000 \mathrm{~kW} / /$ Applied Solar Energy 2017. 54 (2), 99-109

Citation: Odilhuja Parpiev et al., (2020)" Solar Recovery of Metal Alloys", International Journal of Mining Science (IJMS), 6(4), pp. 20-25. DOI: http://doi. org/10.20431/2454-9460.0604003

Copyright: () 2020 Odilhuja Parpiev, This is an open-access article distributed under the terms of the Creative Commons Attribution License, which permits unrestricted use, distribution, and reproduction in any medium, provided the original author and source are credited. 